GA-A22214

$$
\text { CONF-950905- } 49
$$

\title{
EVALUATION OF U.S. DEMO \\ HELIUM-COOLED BLANKET OPTIONS
}

C.P.C. WONG, B.W. MCQUILLAN, R.W. SCHLEICHER,

E.T. CHENG, and THE ARIES TEAM

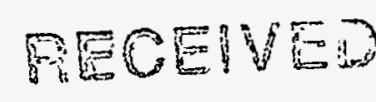

A.8 034997

OSTI

DISTRABUTION OF THS DOCUMENT IS UMUMUTEO

OCTOBER 1995 


\section{DISCLAIMER}

This report was prepared as an account of work sponsored by an agency of the United States Government. Neither the United States Government nor any agency thereof, nor any of their employees, makes any warranty, express or implied, or assumes any legal liability or responsibility for the accuracy, completeness, or usefulness of any information, apparatus, product, or process disclosed, or represents that its use would not infringe privately owned rights. Reference herein to any specific commercial product, process, or service by trade name, trademark, manufacturer, or otherwise, does not necessarily constitute or imply its endorsement, recommendation, or favoring by the United States Government or any agency thereof. The views and opinions of authors expressed herein do not necessarily state or reflect those of the United States Government or any agency thereof. 


\section{DISCLAMMER}

Portions of this document may be illegible in electronic image products. Images are produced from the best available original document. 
GA-A22214

\title{
EVALUATION OF U.S. DEMO \\ HELIUM-COOLED BLANKET OPTIONS
}

\author{
by \\ C.P.C. WONG, B.W. MCQUILLAN, R.W. SCHLEICHER, \\ E.T. CHENG, ${ }^{*}$ and THE ARIES TEAM
}

This is a preprint of a paper presented at the 16th IEEE/NPSS Symposium on Fusion Engineering, September 30-October 5, 1995, Champaign, Illinois, and to be printed in the Proceedings.

*TSI Research Inc., Solana Beach, California

\author{
Work supported by \\ the U.S. Department of Energy \\ under Contract No. DE-AC03-89ER52153
}

GA PROJECT 3469

OCTOBER 1995 


\title{
Evaluation of U.S. Demo Helium-cooled Blanket Options*
}

\author{
C.P.C. Wong, ${ }^{a}$ B.W. McQuillan, ${ }^{a}$ R.W. Schleicher, ${ }^{a}$ E.T. Cheng, ${ }^{b}$ and the ARIES Team

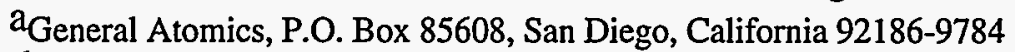

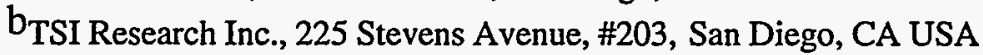

\begin{abstract}
A He-V-Li blanket design was developed as a candidate for the U.S. fusion demonstration power plant. This paper presents an $18 \mathrm{MPa}$ helium-cooled, lithium breeder, V-alloy design that can be coupled to the Brayton cycle with a gross efficiency of $46 \%$. The critical issue of designing to high gas pressure and the compatibility between helium impurities and V-alloy are addressed.
\end{abstract}

\section{INTRODUCTION}

As a part of the Starlite Project, the U.S. Demo Team has identified the mission and design requirements of U.S. fusion demonstration power plants. Demo must satisfy the minimum design requirements and embody the minimum technological extrapolation required to achieve the Demo Mission. Evaluation was performed on helium-cooled, vanadium-alloy blanket options. Low activation vanadium-alloy is selected as the structural material because of its higher temperature performance potential compared with ferritic steel alloy, and its possibility of reaching matured development before the construction and operation of the U.S. Demo by the year 2025. The motivations for the use of helium as the blanket coolant are its potential for high thermal efficiency and properties of chemical inertness and non-activation. It is the only coolant used by advanced fission reactors that has the thermodynamic and transport properties that allow high temperature and hence high efficiency operation with high temperature structural material, leading to the possible use of a Brayton cycle power conversion system. Its properties of chemical inertness and non-activation significantly reduces the risk of chemical safety and waste disposal. In order to realize these advantages, the helium design must work with its property of relatively low volumetric specific heat, which means addressing the high pressure system design issues. The design must also successfully address the issue of compatibility between V-alloy and helium impurities.

\section{A REVIEW}

Two helium-cooled blanket designs have been proposed previously for use with V-alloy.

The first design is the helium-cooled, V-alloy structure blanket option proposed for ITER [1]. It is a poloidal coolant flow, co-axial U-shape tube, molten lithium, breeder-out-of- tube (BOT) design, with narrow modules that could fit the narrow vertical maintenance opening of the 1993 ITER-EDA design. This design focused on addressing the question of reliability when high pressure helium (18 $\mathrm{MPa}$ ) is used. All piping joints are located outside of the vacuum vessel. Coaxial tubes were used to increase design reliability. Both coaxial tubes are designed to take the full helium pressure and only the inner tube was pressurized. The annulus between tubes was filled with liquid metal $(\mathrm{Na}$ or $\mathrm{Li}$ ) for leak detection. This option addresses many of the design issues, but not the issue of material compatibility between V-alloy and helium-impurities.

The second design reviewed is the reference SEAFP reactor study [2]. This blanket is a poloidal flow, co-axial tube, $\mathrm{Li}_{2} \mathrm{O}$ breeder-in-tube (BIT) design. The solid breeder $\mathrm{Li}_{2} \mathrm{O}$ is also used to fill-in the space between co-axial tubes. Helium coolant at $9 \mathrm{MPa}$, flows in the annulus between the co-axial tubes. The key focus of the SEAFP design is to ensure public acceptance and take into account the operating requirements of utilities. The issue of material compatibility between $\mathrm{V}$-alloy/ $\mathrm{Li}_{2} \mathrm{O}$ and $\mathrm{V}$-alloy/helium-impurities interfaces is proposed to be resolved by coatings of sub-micron thick SiC or $\mathrm{Al}_{2} \mathrm{O}_{3}$.

\section{THE He-Li-V DEMO DESIGN}

\section{A. Design description}

Considering the advantages and disadvantages of previous V-alloy helium-cooled designs, a new helium-cooled, molten lithium, V-alloy design (He-Li-V) was developed for Demo. It is a toroidal flow, single wall coolant tube, stagnant $\mathrm{Li}$ breeder design as shown in Figs. 1 and 2. Similar to the ITER design, the use of molten Li-breeder eliminates all the fabrication and operation difficulties related to the use of solid breeders. Some of these difficulties are: the fabrication of sphere-pac or sintered pellets, uniform filling of solid in tortuous channels, loss of blanket volume due to void fraction, radiation damage of solid breeder, solid-to-solid thermal contact resistance, sphere-pac settling and thermal ratcheting effects; and the complexity of tritium purge flow system design. For this He-Li-V design, the breeder lithium should be circulated slowly for tritium extraction, MHD insulation may not be necessary. The blanket module consists of blanket boxes connected to the coolant plenum and structural support located at the back of the blanket. Tube plates

\footnotetext{
*Work supported by the U.S. Department of Energy under Contract No. DE-AC03-89ER52153.
} 


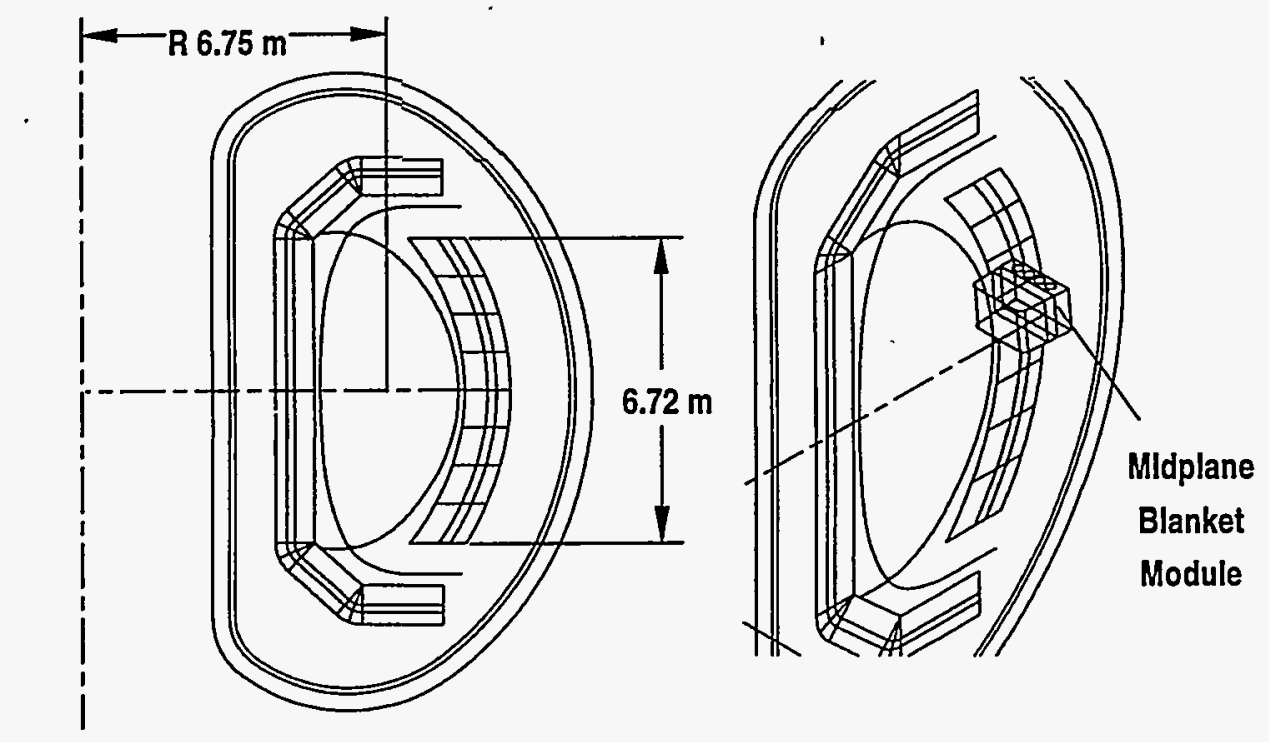

Fig 1. Cross section of a Demo tokamak

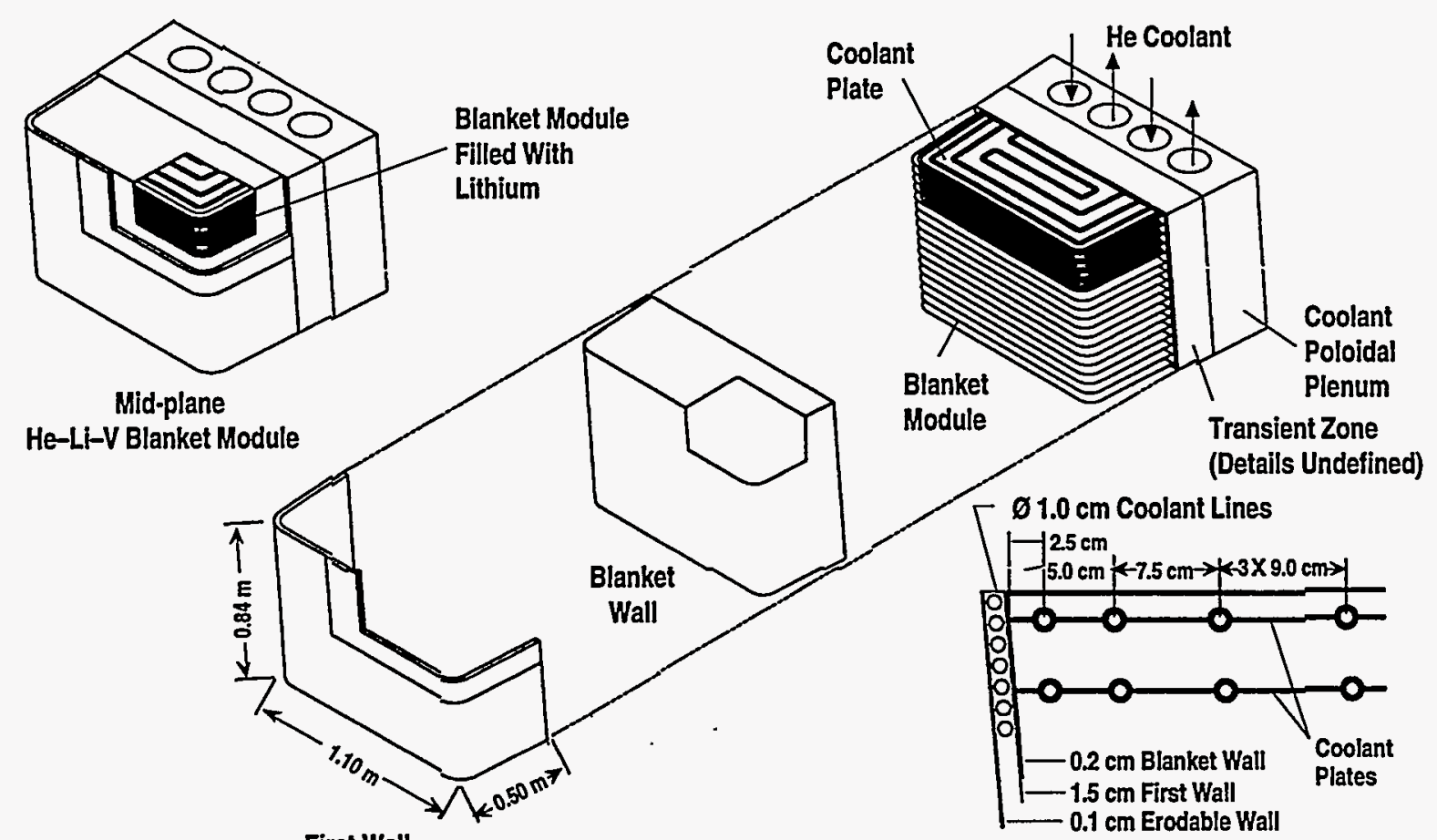

(Toroidal Flow Channels)

First Wall and Blanket Tubing Arrangement

Fig. 2. He-Li-V blanket module

can be formed by imbedding coolant tubes in V-alloy sheets by diffusive bonding. This tube plate arrangement is similar to the ferritic steel solid breeder design [3] proposed by KfK. Between the cooling tube plates the module is filled with molten lithium maintained at atmospheric pressure connected to a common channel and then to the free surface of each poloidal sector. The coolant is routed from the back poloidal plenum to cool the first wall and then re-routed to cool the rest of the blanket. This routing scheme is selected to maximize the coolant outlet temperature to achieve the highest possible thermal conversion efficiency. The key $\mathrm{He}-\mathrm{Li}-\mathrm{V}$ blanket design parameters is given in Table I. 
Table I

Selected Input and Output Parameters for the He-Li-V Blanketed Design

$\mathrm{R}, \mathrm{m}$.

6.75

a, $\mathrm{m}$

Elongation

1.5

2.03

1925

Eusion power, MW

Average surface heat flux, $\mathrm{MW} / \mathrm{m}^{2}$

Average neutron loading, $\mathrm{MW} / \mathrm{m}^{2}$

Surface loading peaking factor

Structural material

Tritium breeder

Helium pressure, $\mathrm{MPa}$

Inlet-helium temperature, ${ }^{\circ} \mathrm{C}$

Outlet helium temperature, ${ }^{\circ} \mathrm{C}$

0.336

2.9

1.67

V-alloy

$\mathrm{Li}$

18

400

650

$46 \%$

$1.402(1-D)$

Tritium breeding ratio

First wall maximum temperature, ${ }^{\circ} \mathrm{C}$

Blanket front wall V-alloy max. temp., ${ }^{\circ} \mathrm{C}$

611

657

First wall primary stress, $\mathrm{MPa}$

47

First wall total stress (primary+secondary), $\mathrm{MPa}$

\section{B. Neutronics performance}

A major radius model calculation was performed for the HeV-Li option. The material volume fractions were determined after two iterations between the configurational design, scoping thermal-hydraulics and neutronics calculations. The first wall and first layer of breeder is $3 \mathrm{~cm}$ thick and the rest of the blankets are $28 \mathrm{~cm}$ and $48 \mathrm{~cm}$ thick, respectively, for the inboard and outboard blankets. The first wall and blanket tubes are 1 and $1.5 \mathrm{~cm}$ in diameter, respectively. The V-alloy volume fraction is about $7 \%$ and the lithium radial volume fraction distribution has a range of $79 \%$ to $92 \%$. The remaining space is taken up by helium as void. The 1-D tritium breeding ratio is 1.402 and the total nuclear heating is
$16.02 \mathrm{MeV}$ per D-T neutron. These results show that the He$\mathrm{V}$-Li design has the potential of producing adequate tritium breeding without the use of neutron multiplier. The power density of different blanket materials are quite acceptable when all the temperature limits are met.

\section{Thermal-hydraulics results}

Based on neutronics results of detailed radial volumetric power density distribution, scoping thermal-hydraulic calculations were performed to assess the materials maximum temperatures, and coolant frictional pressure drops for the blanket and first wall. The primary and secondary stresses of the first wall was also estimated by the simple model of a circular tube. Peak surface and neutron wall loading assumptions were used for the maximum temperature calculations. Table I indicates that the $\mathrm{V}$-alloy maximum temperature can be maintained to $<700^{\circ} \mathrm{C}$. All primary $(<105 \mathrm{MPa})$ and total stress ( $<315 \mathrm{MPa}$ ) limits, as modeled by a long cylinder, can also be met.

\section{Power conversion performance}

Fig. 3 shows a schematic of the blanket coolant coupled to a direct helium Brayton cycle for power production. At a helium outlet temperature of $650^{\circ} \mathrm{C}$ a gross efficiency of $46 \%$ can be attained. The reason for this high efficiency is due partly to the high helium pressure and the assumption of a $96 \%$ effective recuperator. Fig. 4 shows the relationship between gross thermal efficiency and temperature/pressure for a helium cooled blanket coupled to a Brayton cycle. A

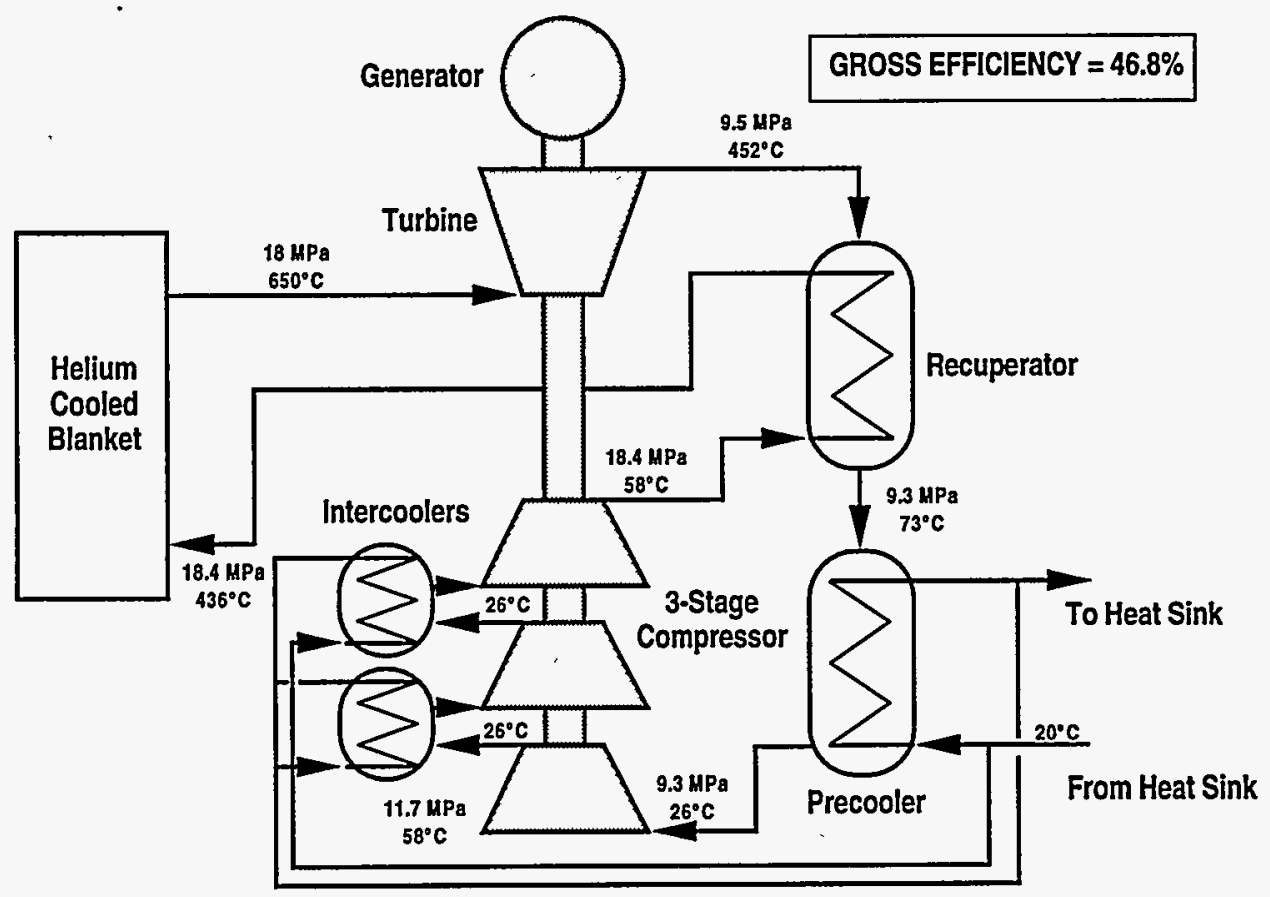

Fig. 3. Fusion demo plant direct helium Brayton cycle power conversion. 


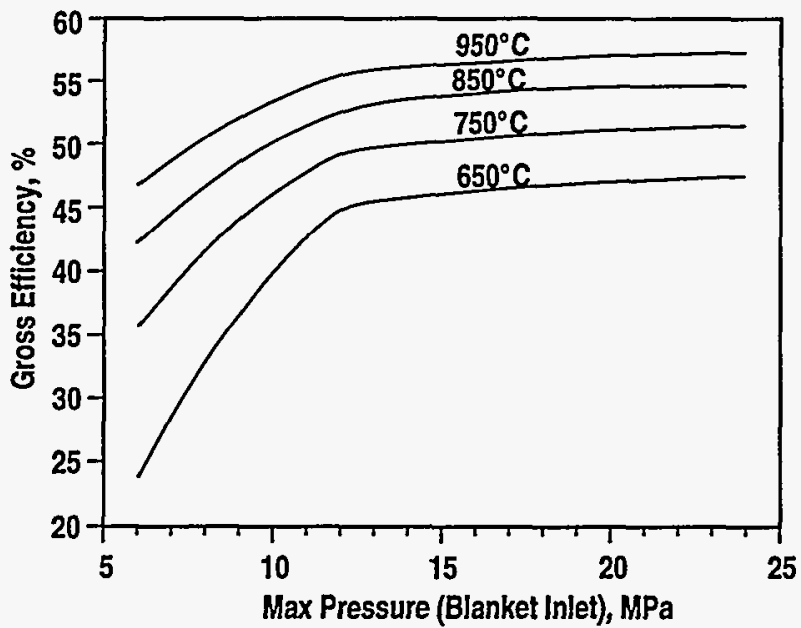

Fig. 4. Demo direct helium Brayton cycle efficiency as a function of maximum helium pressure and temperature.

gross thermal efficiency of $60 \%$ can be achieved with helium outlet temperature in the range of $1100^{\circ} \mathrm{C}$. This is well within the capabilities of current gas turbines which operate at temperatures in the range of $1200^{\circ}-1300^{\circ} \mathrm{C}$. However, it will require an advanced blanket material such as metal matrix composite or advanced $\mathrm{SiC} / \mathrm{SiC}$ composite. Fig. 4 also illustrates the importance of gas pressure on cycle efficiency. Above $12 \mathrm{MPa}$, performance becomes a relatively weak function of pressure. Below that value the pressure losses through the blanket becomes a dominating effect. The selected gas pressure at $18 \mathrm{MPa}$ is for the goal of further blanket pressure drop reduction.

\section{CRITICAL ISSUES}

As presented above the use of V-alloy and helium coolant has the potential to be a high thermal performance low activation blanket design. Two critical issues remain to be addressed. These are the operation with high helium pressure and the compatibility between V-alloy and helium impurities.

\section{A. Design with high pressure helium}

A system pressure of $18 \mathrm{MPa}$ is relatively high, but by no means unusual by modern industrial standards. It is important to understand that the probability of a leak is a weak function of gas pressure. Rather it is mainly a function of the incidence of undetected critical flaws and a crack propagation mechanism such as creep or high or low cycle fatigue. Stresses from these mechanism are much greater than primary (pressure induced) stresses. Current design practice, used in the utility and process industries, employs established calculational procedures to determine critical flaw sizes and inspection techniques to detect the presence of critical flaws. Via this approach, highly reliable operation of high pressure systems has been achieved. For example hundreds of commercial superheated steam systems are operating in the range of $17-20 \mathrm{MPa}$ and a lesser number of supercritical steam systems are operating in the range of $24 \mathrm{MPa}$. Natural gas line pumping units operate at pressures to $27.5 \mathrm{MPa}$. What is significant about the helium-cooled blanket is that it operates next to a system with stringent vacuum conditions. Thus, special care must be taken to assure that leaks are improbable to maintain high machine reliability and availability; and that large leaks (such as tube rupture) are highly improbable for investment protection. To accomplish these, first the incidence of small leaks must be designed to be very low. This is achieved by a thorough, robust design. Second, if a small leak occurs, it must not rapidly propagate to a large leak before action is taken to valve off the high pressure gas, to prevent any significant damage to the blanket module.

In 1993, General Atomics applied the technique of leakbefore-break assessment [1] on the helium-cooled blanket design for ITER. The material used was V-alloy, the helium pressure was set at $20 \mathrm{MPa}$, and the helium-cooling tubes were designed to 100,000 full power shots. In terms of operation, this large number of cycles is a much more severe requirement than what is required for the U.S. Demo design, which should be a steady state device with fewer than 50 cycles for a 5 year life first wall. In this ITER blanket design exercise, conservative assumptions were made in the calculations of crack propagation. A value of $\mathrm{K}_{\mathrm{IC}}$ reduced by irradiation to $40 \mathrm{MPa}-\mathrm{m}^{1 / 2}$ was assumed for the critical crack length calculation. (This is the irradiated lower shelf value for HT-9. This is a conservative value for V-alloy because of its superior ductility at higher temperature than HT-9.) Analyses were performed for different ITER tubes at different loading conditions. The surface loadings were for the cases of 0.35 and $1 \mathrm{MW} / \mathrm{m}^{2}$. Results showed that an initial undetected flaw of $<0.9 \mathrm{~mm}$ depth would not produce leakage in $<100,000$ cycles (i.e. each burn cycle equal to 1000s). This is a large initial flaw and can be assumed to have a very low probability of occurrence, because manufacturing techniques and QC inspection would not allow such a flaw to exist in the base material. In addition, results showed nearly all the failure scenarios met the leak-before-break criteria. 
To ensure the application of the leak-before-break technique and to avoid cooling tube bursting, it is necessary to derive a helium leakage detection technique for the He-Li-V design. Calculations show that at $2000 \mathrm{MW}$ fusion power, the generation rate of helium in the lithium breeder, from $(n, \alpha)$ reaction, is about $0.005 \mathrm{gm} / \mathrm{s}$, and with a flaw size in the range of 0.1 to $0.5 \mathrm{~mm}$ diameter (less than the critical flaw size of $0.9 \mathrm{~mm}$ ) the helium leakage rate can be estimated to be in the range of $0.05 \mathrm{~g} / \mathrm{s}$ to $1.2 \mathrm{~g} / \mathrm{s}$, respectively, which are much larger than the fusion helium generation rate in lithium. This means that the helium leakage from the primary coolant can be distinguished and detected before the flaw size becomes critical. For investment protection, it is necessary to design the module to withstand a certain value of over pressurization. A separate estimate has shown that the blanket module can be designed to withstand a short duration of module over pressure to about $9 \mathrm{MPa}$ to before the activation of the passive shut-off valves within a duration of $0.1-0.5 \mathrm{~s}$, will be necessary.

\section{B. Helium impurities compatibility with V-alloy}

Both helium and lithium are compatible with V-alloy through the entire proposed temperature range of the He-Li- $\mathrm{V}$ design. However, when helium is used as the coolant with V-alloy, the possibility of helium impurities $(\mathrm{O}$ or $\mathrm{H})$ reacting with $\mathrm{V}$-alloy was identified as a critical issue in the 1983-84 BCSS [4] study. Since then there has not been any systematic program to address this issue. Uncoordinated studies have continued, mostly performed at relatively high concentration of moisture ( $100 \mathrm{ppm})$ content, atmospheric pressure oxygen or air at high temperature. Since at this time there are no conclusive experimental results that can address this issue of compatibility, it becomes important to review gas cooled fission reactor experience in the areas of impurities extraction and impurity ingress control. The approaches of metallic surface modification and oxidation resistant alloy can also be considered when necessary.

\section{Impurity removal}

The technology for impurity cleanup in helium coolant loops has been well demonstrated in operating gas-cooled, fission reactors. Experience in the U.S. and Europe has demonstrated systems with reliable side stream cleanup of impurity particulate, moisture and gases using systems readily available to the blanket cooling application. A typical helium purification train similar to what could be deployed as a part of a blanket cooling system, consists of four factory fabricated process modules. The modules and their functions are: 1.) High temperature filter/absorber, consists of an activated charcoal bed followed by a metallic filter elements. Particulate (i.e., dust) is mechanically trapped by both the charcoal bed and metallic filter elements. 2.) Oxidizer is used to convert hydrogen, tritiated hydrogen and carbon monoxide to water and carbon dioxide for subsequent removal. Oxidation takes place at elevated temperatures as the helium passes through an appropriate catalyst bed. 3.) Dryer can be used to essenti- ally completely remove various form of oxides at this stage by a molecular sieve. In the event of high tritium levels, separate water and carbon dioxide absorber cartridges could be utilized. 4.) Low temperature absorber is used to remove remaining gaseous impurities such as nitrogen and any methane by passing the helium stream through a liquid nitrogen cooled, activated charcoal bed. Purification systems processing more than $2000 \mathrm{~kg}$ of helium per hour are well within existing experience base and would provide rapid coolant turnover, perhaps on the order of one to several hours, if so required.

\section{Control of impurity ingress}

In addition to cleanup, helium purity is dependent on impurity ingress. Precluding or tightly controlling impurity ingress is requisite to maintaining coolant purity. Experience with U.S. and European helium cooled reactors has demonstrated the practicality of achieving low impurity levels. As an example, the German THTR reactor [5] has demonstrated control of $\mathrm{H}_{2} \mathrm{O}$ to $<0.01 \mathrm{ppm}$ by volume, and $\mathrm{H}_{2}$ to $<0.8 \mathrm{ppm}$ by volume. In the high gas pressure He-V-Li blanket, all metallic cooling system, most of the fission reactor conventional impurity sources can be eliminated. Steam generators are eliminated by adoption of the high efficiency Brayton Cycle (DCGT). This system is hermetically sealed to prevent any leakage during operation, but if a leak should occur, helium at a minimum of $9 \mathrm{MPa}$ would leak out rather than air leaking in. Molecular counter diffusion of $\mathrm{O}_{2}$ through the leak (low pressure) would be insignificant. Likewise, leakage of water from the precooler or intercooler is preluded by the fact that the pressure of the helium ( $9 \mathrm{MPa}$ ) is far greater than the water $(0.2-0.3 \mathrm{MPa})$. Any leak would rapidly be detected by the presence of helium in the water. Graphite blocks and fibrous insulation for the fission reactor are not required in a blanket cooling system. This eliminates significant sources of helium impurities. Finally the maturation of magnetic bearing technology eliminates the potential for ingress of rotating machine lubricants.

Hence, the lack of ingress sources coupled with a continuously operating purification system suggest that impurity levels very much lower (perhaps several orders of magnitude) than those observed in helium cooled fission reactors might reasonably be expected.

\section{E. Surface modification}

Although we believe the issue of compatibility can be addressed by impurities extraction and control of impurity ingress. Since at this time there is no experimental data to demonstrate the acceptable equilibrium concentration of low level of impurities in the helium primary loop of the He-V-Li blanket design, it is reasonable to investigate various ways to mitigate the problem if warranted.

A possible way to make the V-alloy compatible with impurities is by way of surface modification. Surface modification 
to address V-alloy chemical compatibility has been investigated by various scoping studies $[6,7]$. In one case, aluminum was used to modify the surface of $\mathrm{V} 5 \mathrm{Cr} 5 \mathrm{Ti}$ to make an $\mathrm{Al}$ rich surface region of the $\mathrm{V}$-alloy. This aluminized $\mathrm{V}$-alloy had dramatically increased oxidation resistance at temperatures to $575^{\circ} \mathrm{C}$ in air when compared to standard V5Cr5Ti material [6] In another case, chromium surface modification was used for a $\mathrm{V} 15 \mathrm{Cr} 5 \mathrm{Ti}$ alloy to dramatically increase oxi-dation resistance, relative to standard $\mathrm{V} 15 \mathrm{Cr} 5 \mathrm{Ti}$, upon exposure to $\mathrm{He}$ containing $100 \mathrm{vppm} \mathrm{H}_{2} \mathrm{O}$ at temperatures to $650^{\circ} \mathrm{C}$ [7]. Chromium surface modified V15Cr5Ti gained $2 \%$ as much weight as V15Cr5Ti upon exposure to $\mathrm{He}$ containing 100 vppm $\mathrm{H}_{2} \mathrm{O}$ at $650^{\circ} \mathrm{C}$ for $400 \mathrm{~h}$. Studies as these show the merit of surface modification of $\mathrm{V}$-alloy structural mater-ial to enhance chemical compatibility. It can be envisioned that for surface modification, if necessary, 10-20 $\mu$ layer of $\mathrm{Si}, \mathrm{Al}$ or $\mathrm{Y}$ can be surface impregnated to the $\mathrm{V}$-alloy surface facing the high pressure helium.

\section{F. Oxidation resistant V-alloy}

Another approach is to make the V-alloy compatible with impurities is to develop oxidation resistant V-alloy. The Japanese have already experimented with additions of up to $1 \%$ by weight $\mathrm{Si}, \mathrm{Al}$, and $\mathrm{Y}$ to bulk $\mathrm{V} 5 \mathrm{Cr} 5 \mathrm{Ti}$ and $\mathrm{V} 15 \mathrm{Cr} 25 \mathrm{Ti}$ materials [8]. They have observed a degree of solutionstrengthening and enhanced oxidation resistance for these bulk modified $\mathrm{V}$-alloys based on measurements performed.

\section{CONCLUSIONS}

As a part of the Starlite Project, the Demo Team has identified the mission and design requirements of the U.S. demonstration power plants. A He-V-Li design concept that can meet these requirements was developed. This design is an $18 \mathrm{MPa}$ helium-cooled design using $\mathrm{V}$-alloy as the structural material, and lithium as the tritium breeder. When combined with a DCGT, a gross thermal efficiency of $46 \%$ can be achieved. The selection of this Brayton cycle system allows the projection of a gross thermal efficiency of $>60 \%$ when advanced struc-tural materials like metal-matrixcomposite or advanced $\mathrm{SiC} / \mathrm{SiC}$-composite material becomes available. To provide a robust high gas pressure system, it is essential to have a conservative design and backup by detailed fabrication procedures and cost effective QC inspection controls already existing in the modern industry. The approach to resolve the issue of compatibility between helium impurities and V-alloy is by continuous coolant clean-up and the control of impurity ingress, which should be relatively easy in this all metallic high gas pressure system. When necessary, this problem can be further eased by the application of surface modification on the V-alloy by using elements like $\mathrm{Si}, \mathrm{Al}$ or $\mathrm{Y}$. In addition, the development of oxidation resistant V-alloy is also being considered. A well coordinated experimental program will be necessary to provide further enlightenment of this compati-bility issue and provide support to this high performance blanket design for the U.S. Demo program.

\section{ACKNOWLEDGMENTS}

Work supported by the U.S. Department of Energy under Contract No. DE-AC03-89ER52153.

\section{REFERENCES}

[1] Wong, C.P.C. et al., "A robust helium-cooled shield/blanket design for ITER," in Proc. of the 15th IEEE/NPSS Symp. on Fusion Engineering, vol. 1, pp. 13-16, 1993. A more detailed GA-summary report, "A Robust ITER Shield/Blanket Design" was distributed around the U.S. in 1993.

[2] Salpietro, E., "Reactor models for safety and environmental assessment of fusion power (SEAFP)." U.S./Japan Workshop on Fusion Power Reactors, Kyoto University, Japan, March 13-17, 1995.

[3] Dalle Donne, M., et al., "European DEMO BOT solid breeder blanket," Kernforschungszentrum, Karlsruhe, KfK5429, November 1994.

[4] Smith, D.L., et al., "Blanket comparison and selection study, final report," Argonne National Laboratory report ANL/FPP-84-1, September 1984.

[5] Baumer R., et al., "THTR commissioning and operating experience,", Energy 16, pp. 59-70, 1991.

[6] Natesan, K., Reed, C.B., and Mattas, R.F., Fusion Eng." and Design 27, 1995.

[7] Tobin, A. and Busch, G. , J. Nucl. Mater. 141-143, (1986), p. 604. C.F.A. Cotton and G. Wilkenson, Advanced Inorganic Chemistry, Interscience Publishers, 3rd Edition, 1972.

[8] Satou, M., "Status of V-Ti-Cr-Si (Al, Y) alloy development," IEA Workshop on Vanadium Alloys for Fusion, Salem OR, June 1994. 